\title{
Characterisation and source identification of biofluorescent aerosol emis- sions over winter and summer periods in the United Kingdom
}

Elizabeth Forde et al.

Correspondence to: Elizabeth Forde (elizabeth.forde@ manchester.ac.uk)

The copyright of individual parts of the supplement might differ from the CC BY 4.0 License. 


\section{Chilbolton Temperature boxplot}
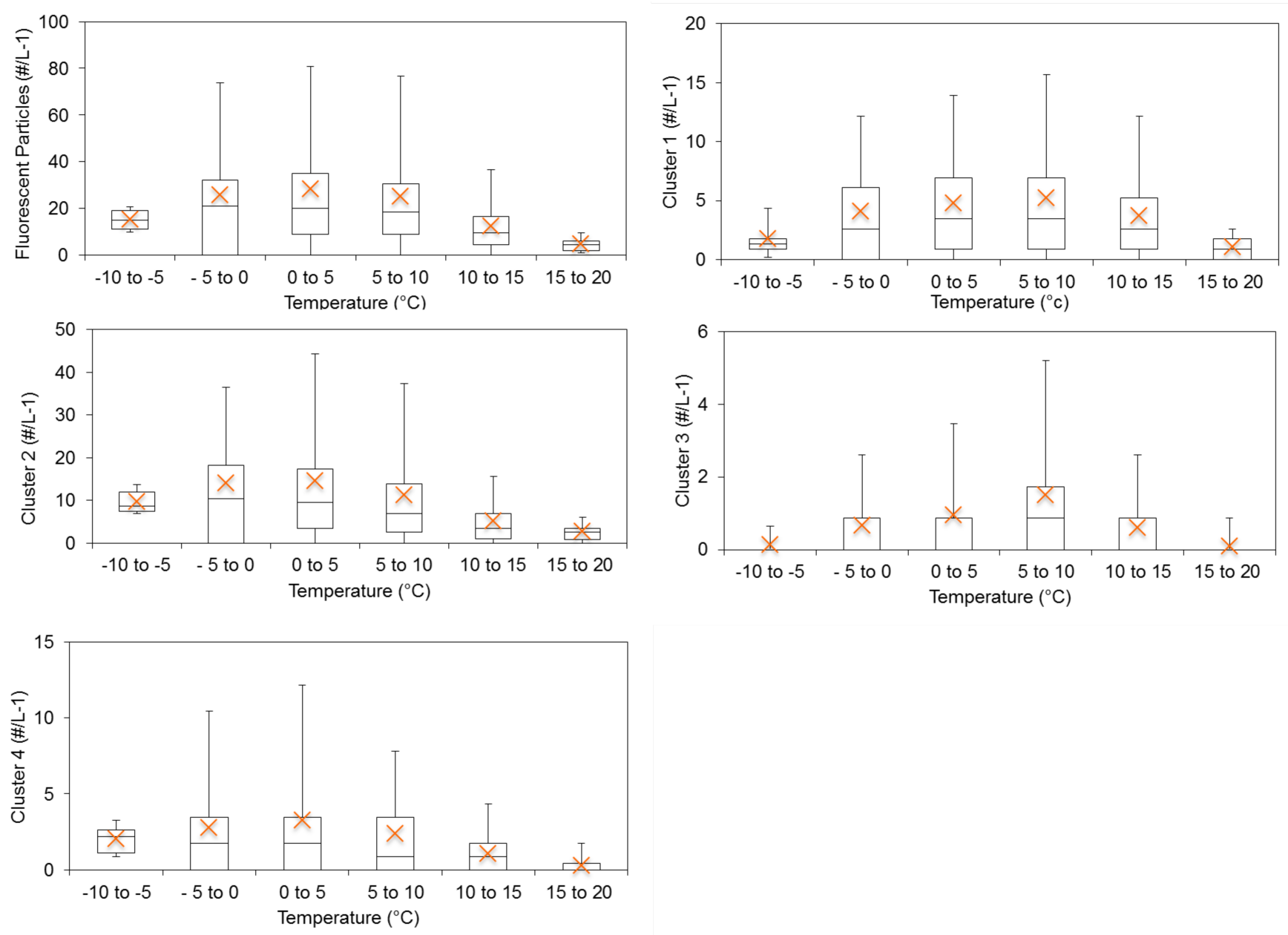

Figure S1: Chilbolton temperature plots in relation to total fluorescent particles and clusters. 


\section{Chilbolton Relative Humidity boxplot}
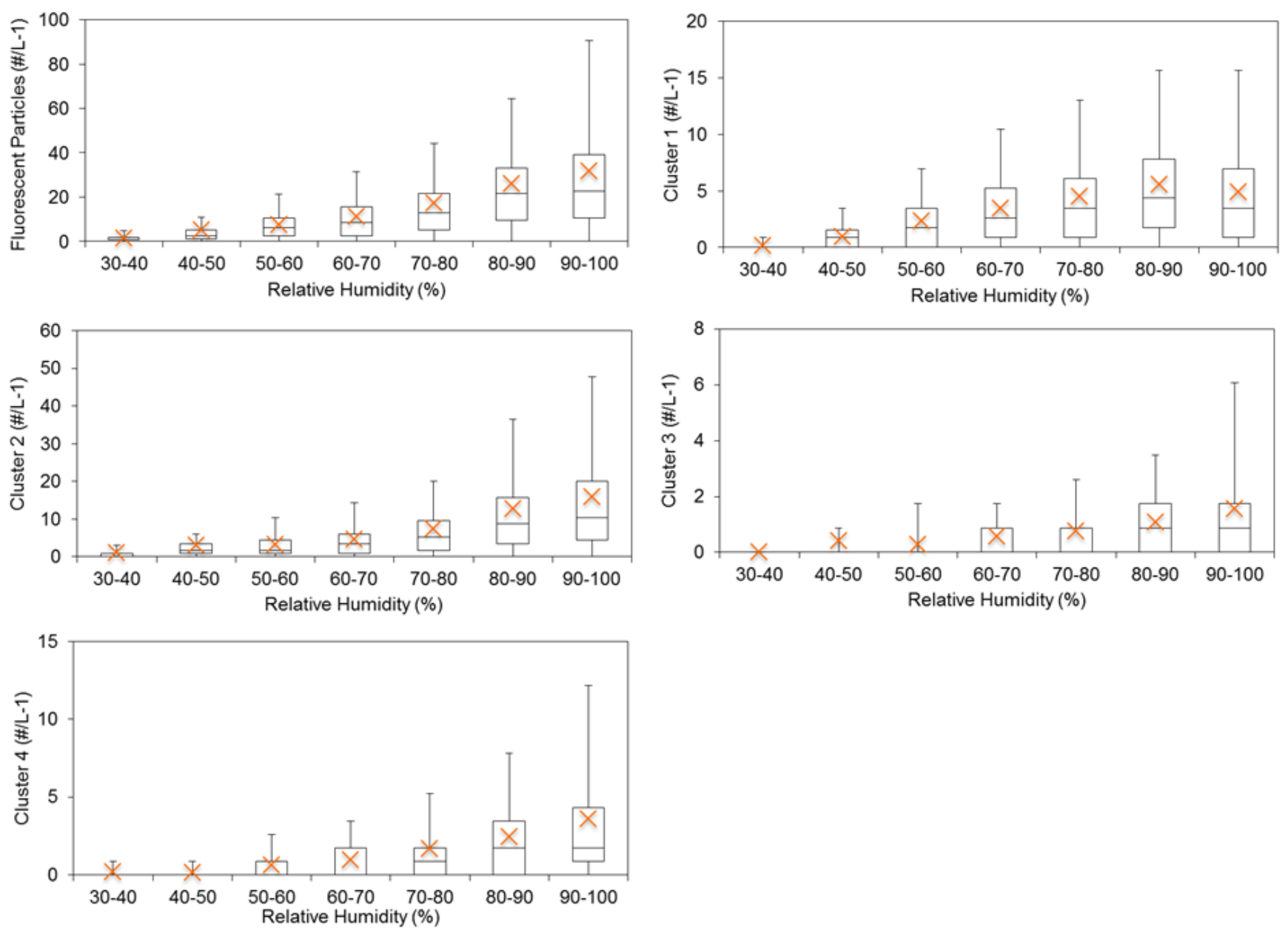

Figure S2: Chilbolton relative humidity plots in relation to total fluorescent particles and clusters. 


\section{Weybourne Temperature boxplot}
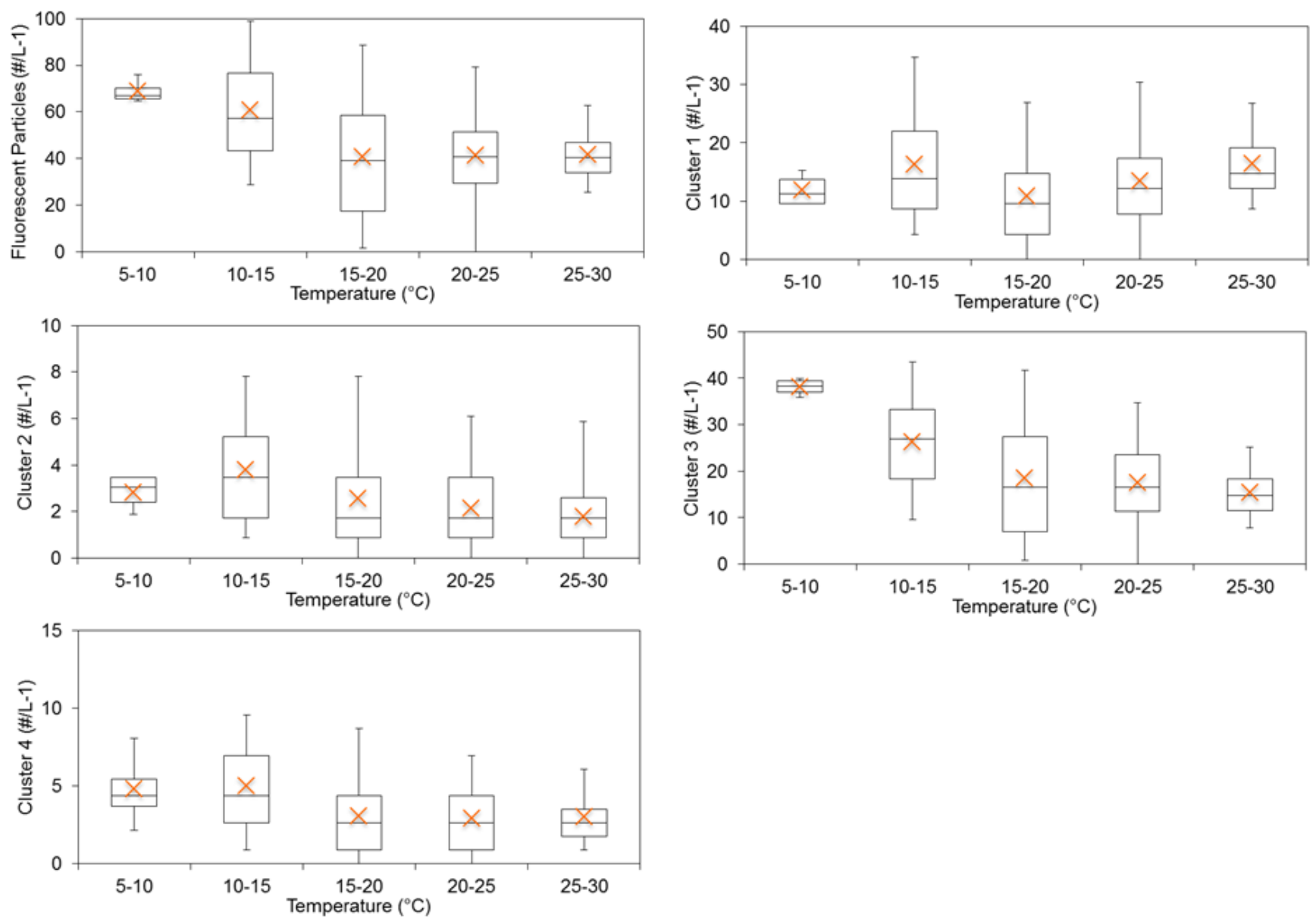

Figure S3: Weybourne temperature plots in relation to total fluorescent particles and clusters. 


\section{Weybourne Relative Humidity boxplot}
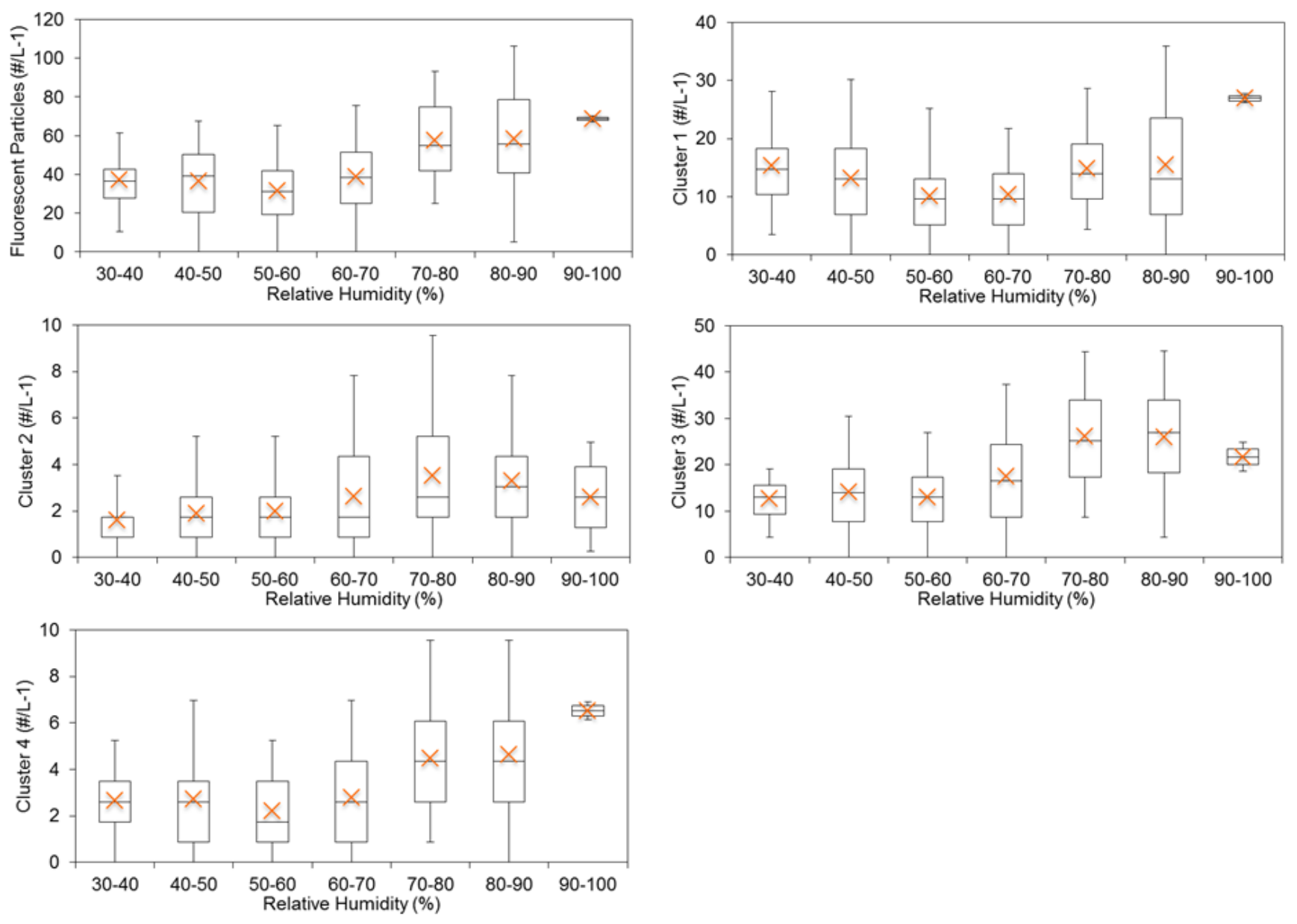

Figure S4: Weybourne relative humidity plots in relation to total fluorescent particles and clusters. 


\section{Davidstow Temperature boxplot}
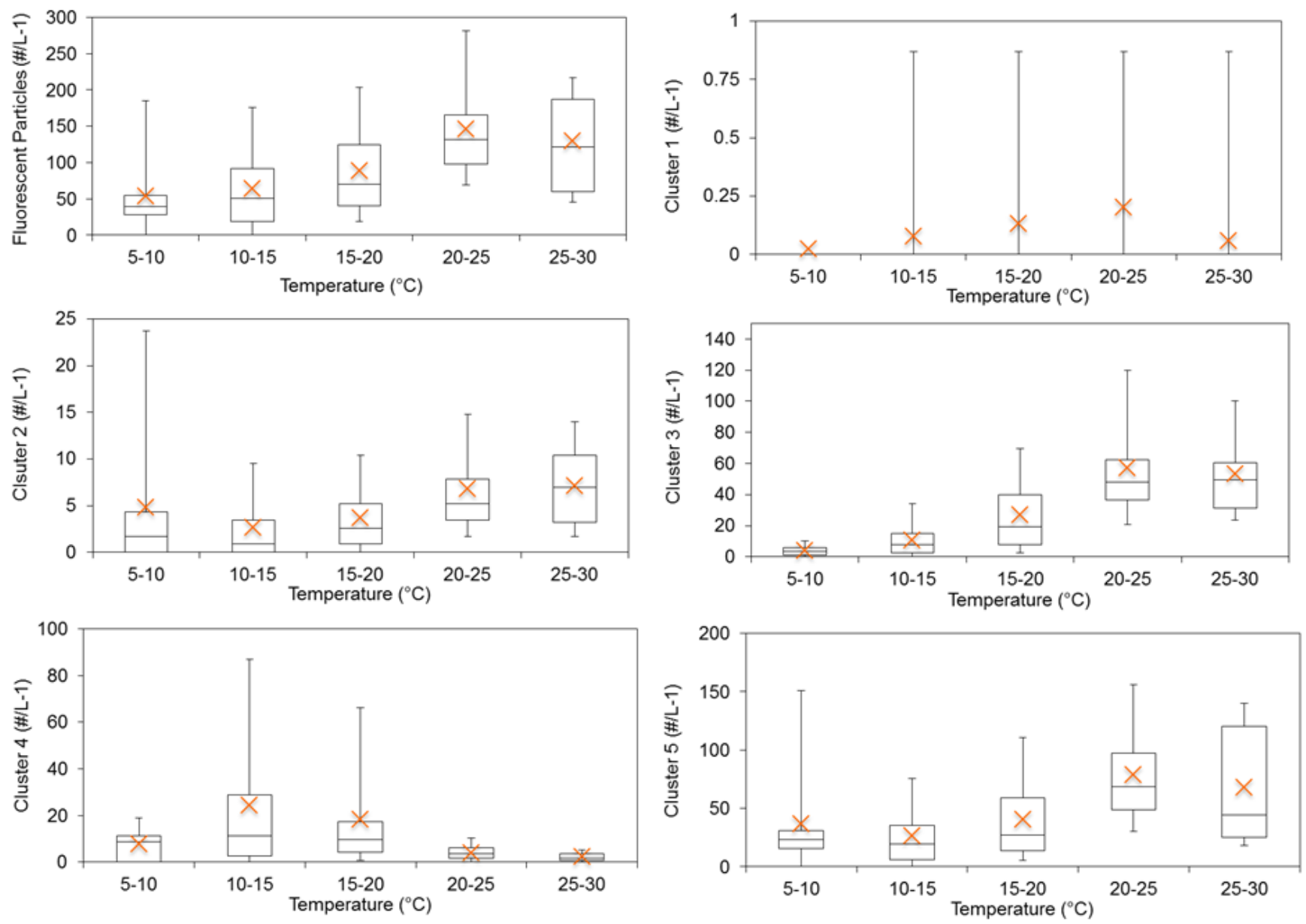

Figure S5: Davidstow temperature plots in relation to total fluorescent particles and clusters. 


\section{Davidstow Relative Humidity boxplot}
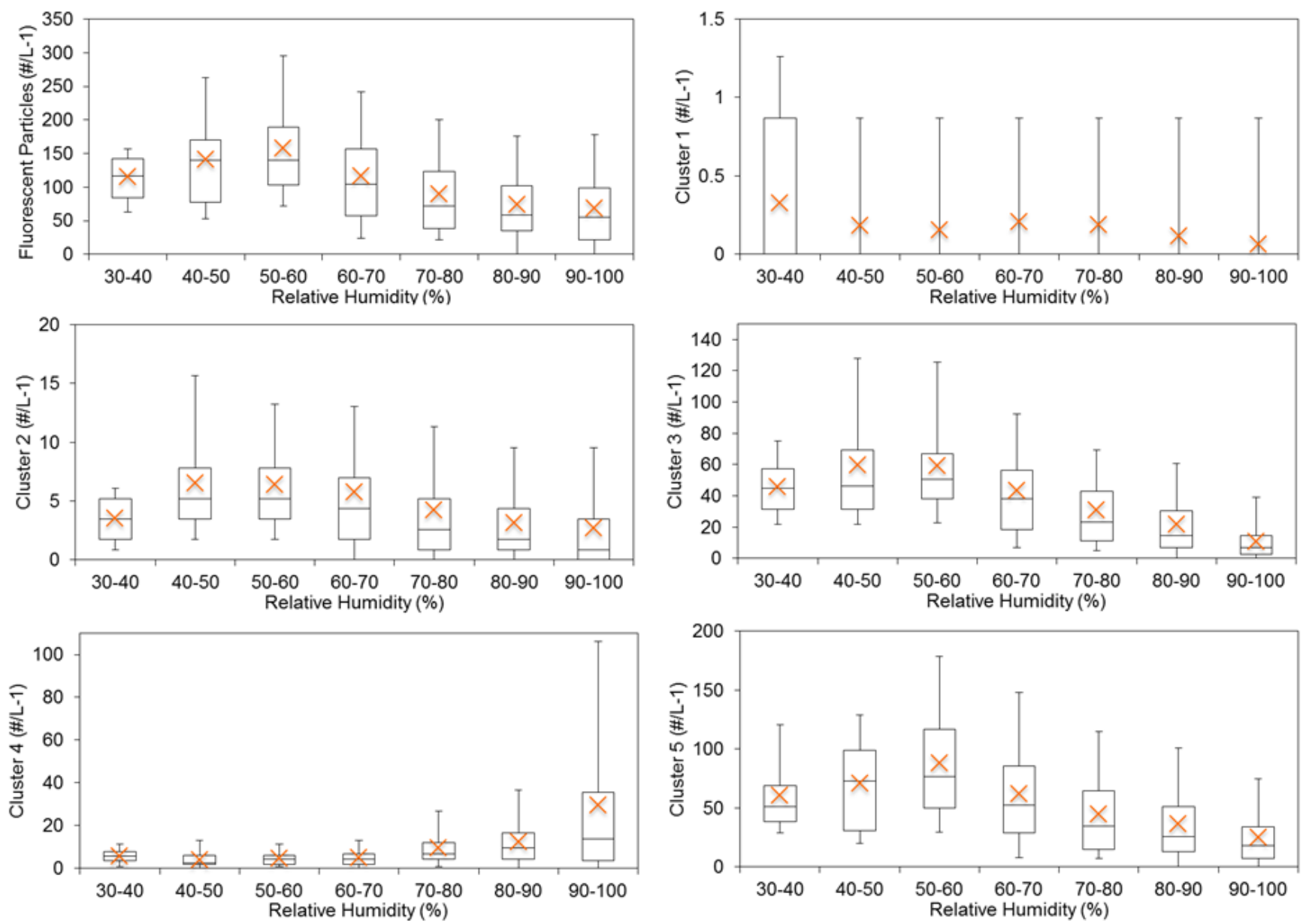

Figure S6: Davidstow relative humidity plots in relation to total fluorescent particles and clusters. 


\section{Capel Dewi Temperature boxplot}
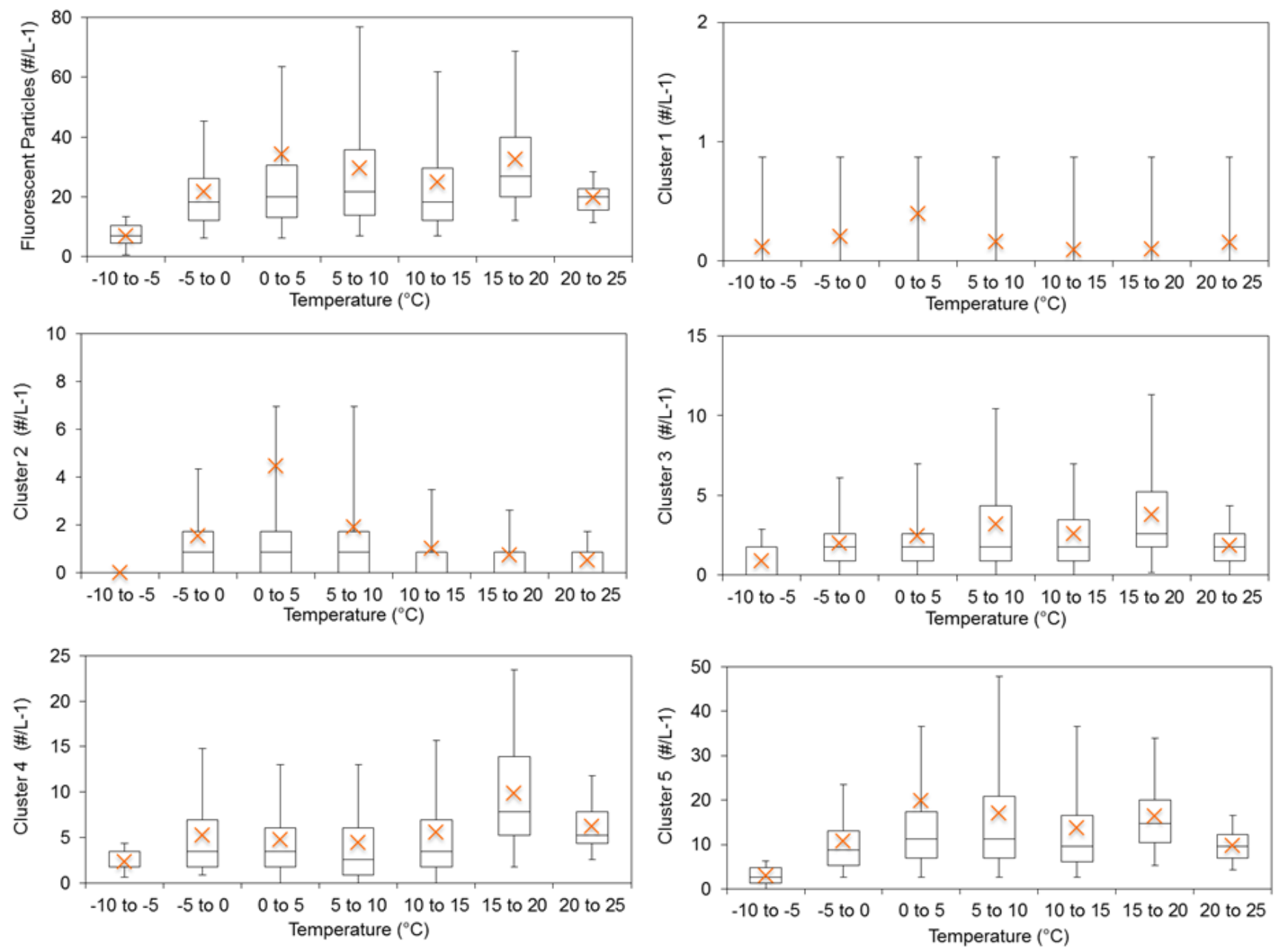

Figure S7: Capel Dewi temperature plots in relation to total fluorescent particles and clusters. 


\section{Capel Dewi Relative Humidity boxplot}
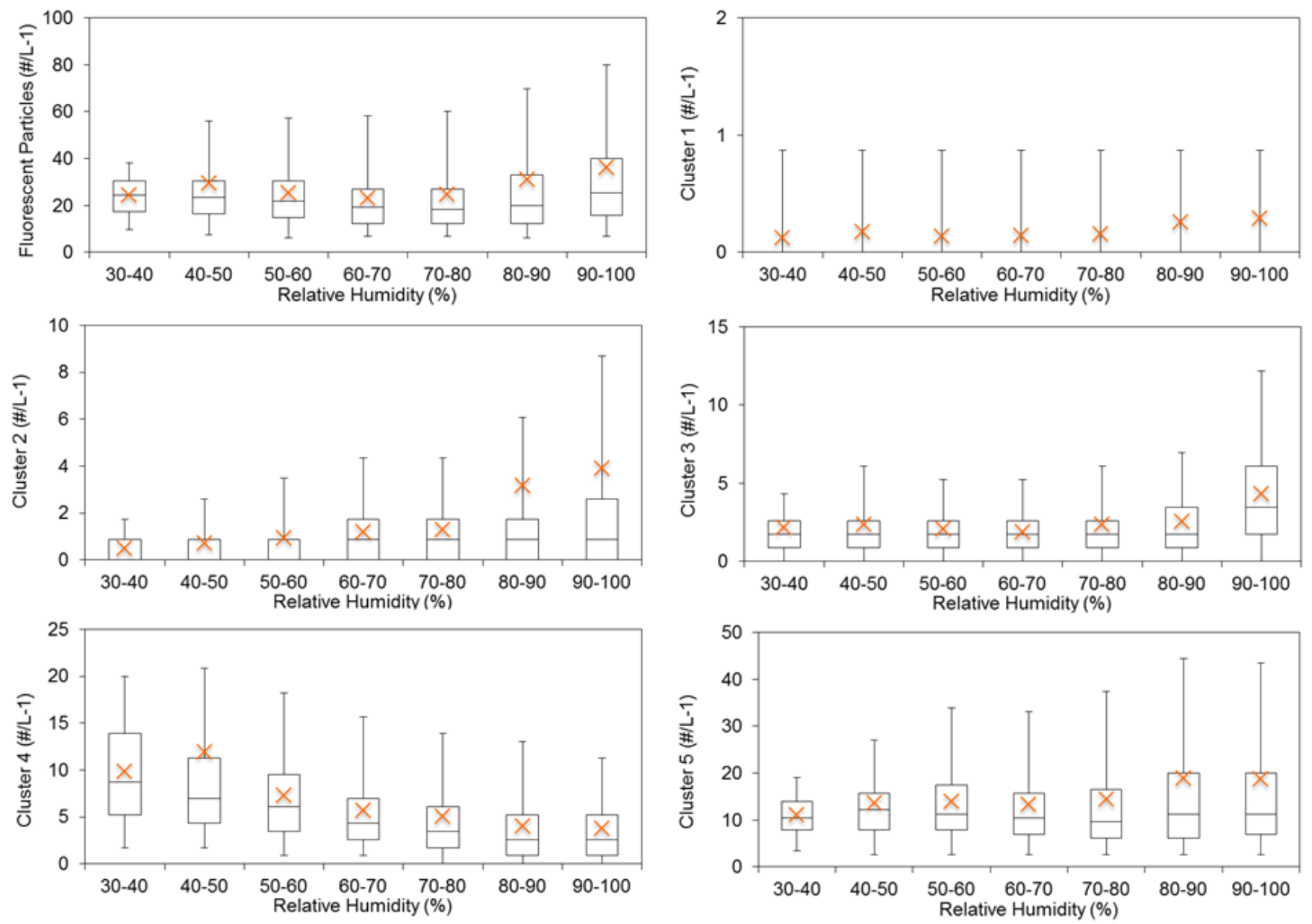

Figure S8: Capel Dewi relative humidity plots in relation to total fluorescent particles and clusters. 


\section{Openair - Chilbolton}
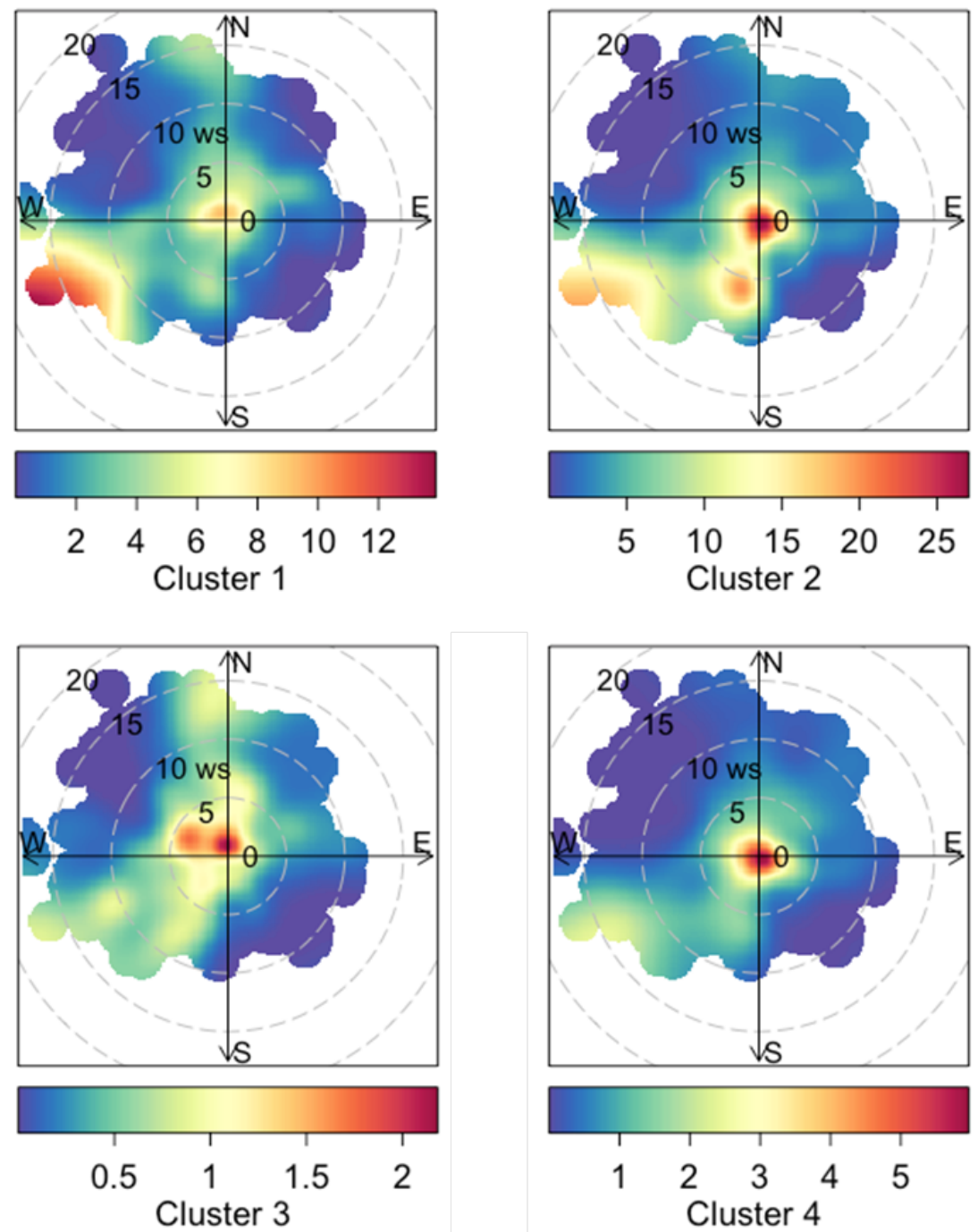

Figure S9: Chilbolton Openair PolarPlots. 


\section{Openair - Weybourne}
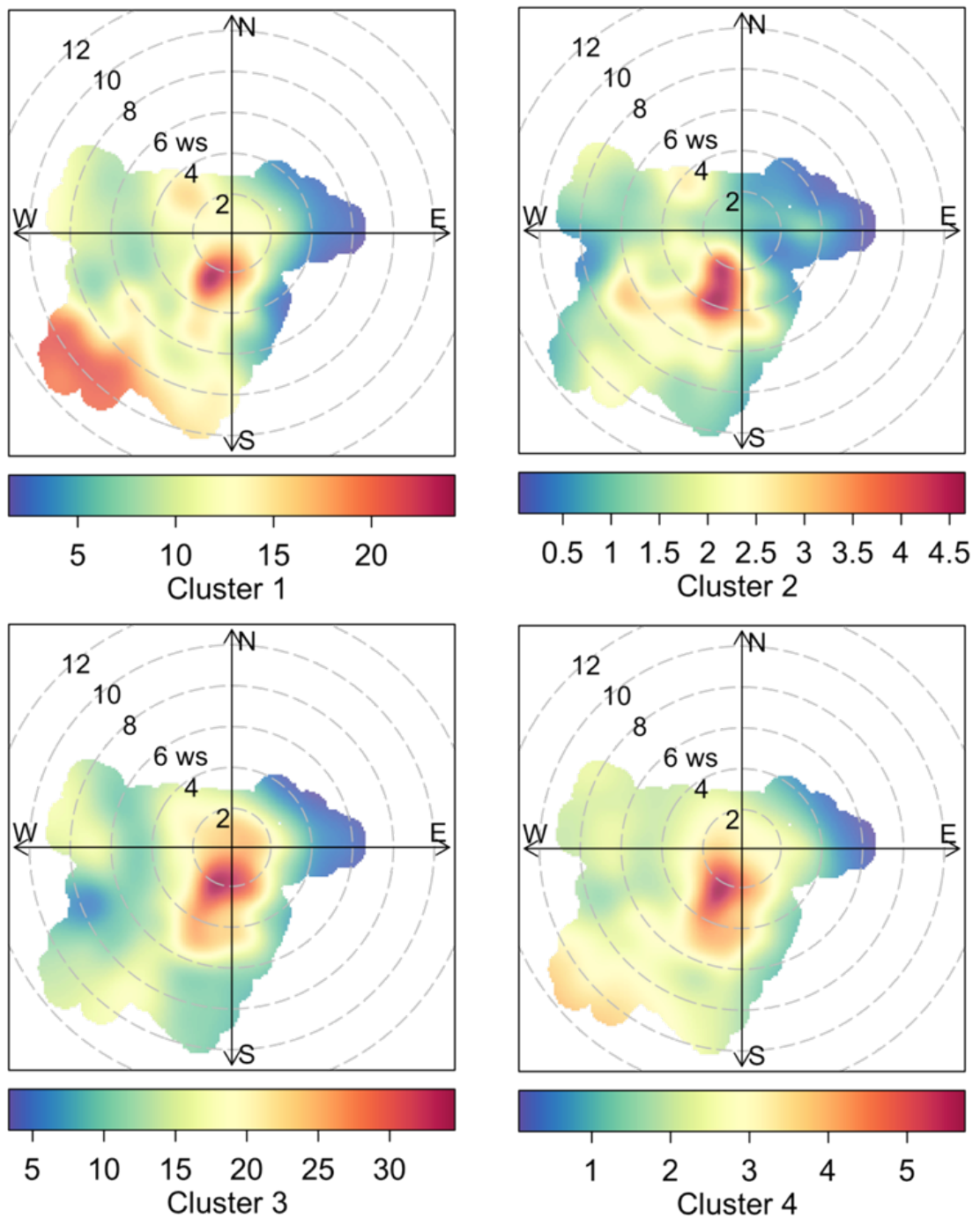

Figure S10: Weybourne Openair PolarPlots. 


\section{Openair - Davidstow}
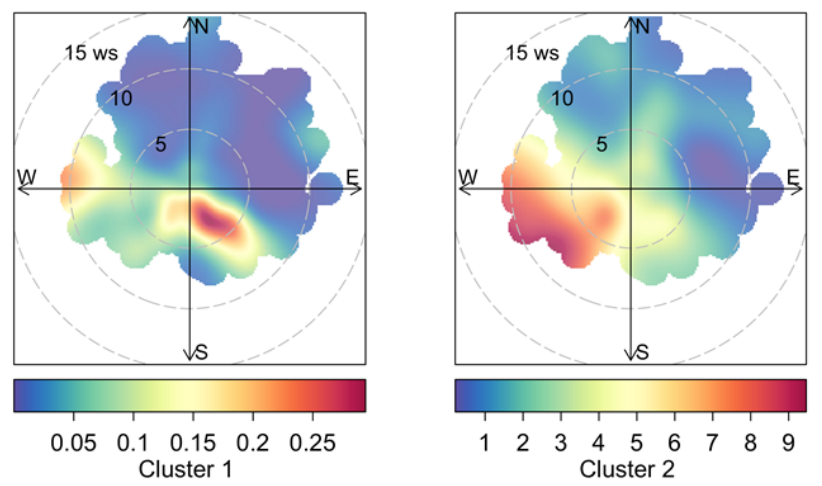

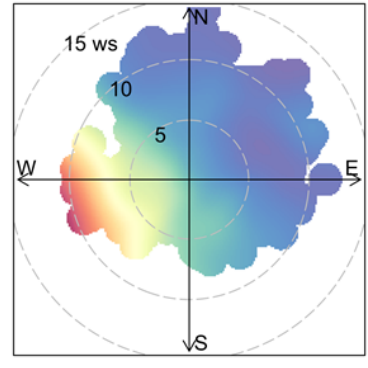

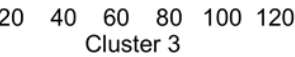
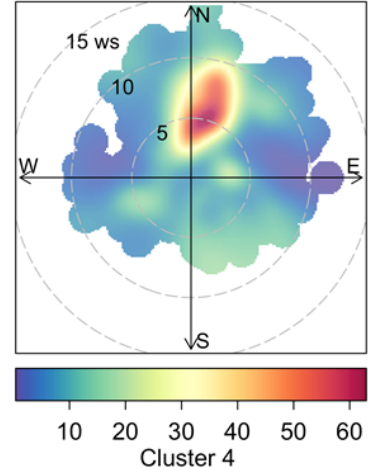

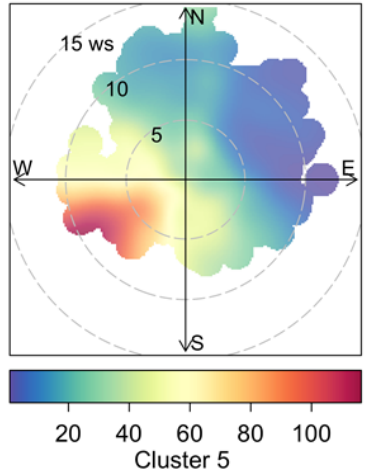

Figure S11: Davidstow Openair PolarPlots. 


\section{Openair - Capel Dewi}
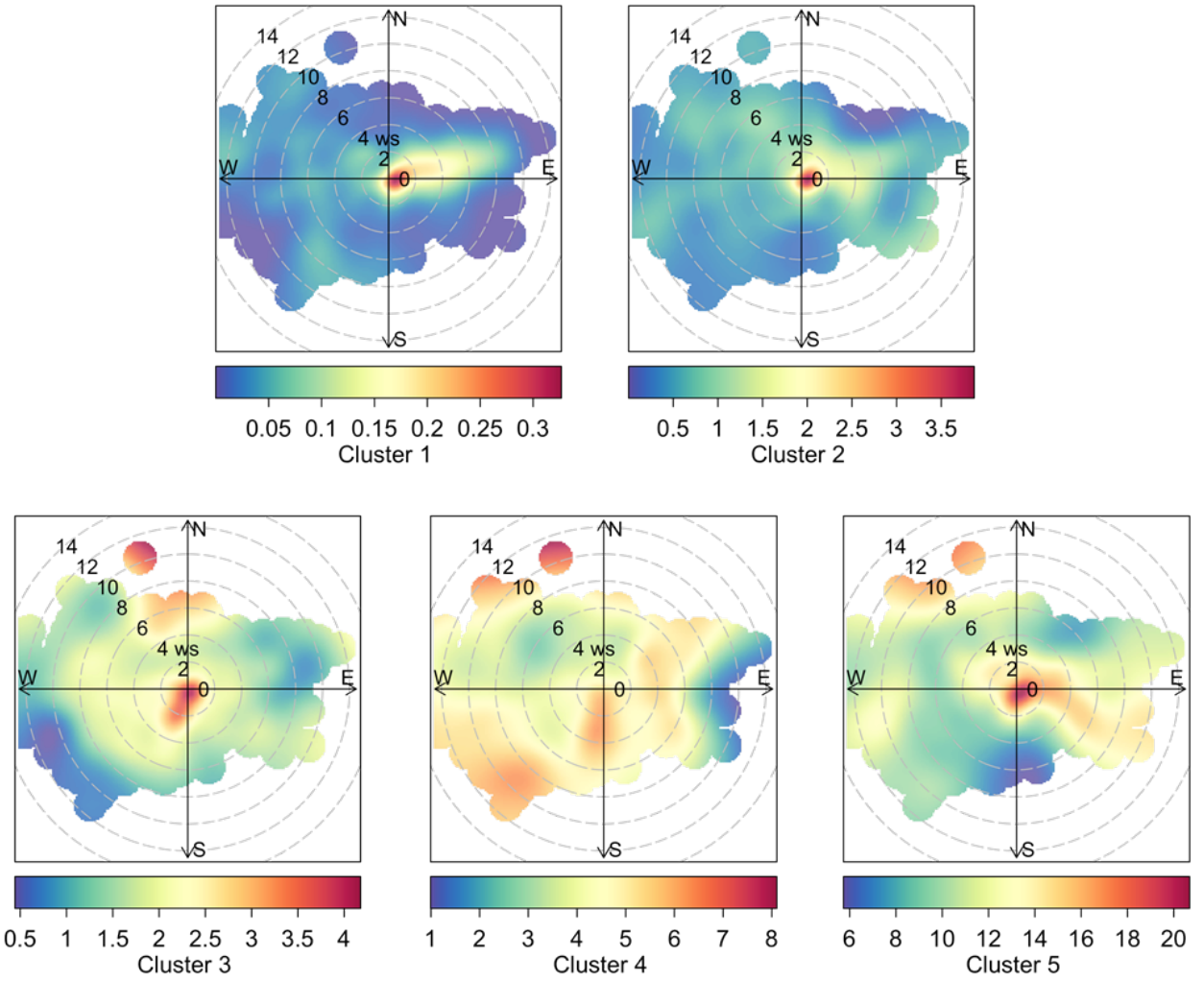

Figure S12: Capel Dewi Openair PolarPlots. 


\section{FT + 3SD/9SD - Chilbolton}
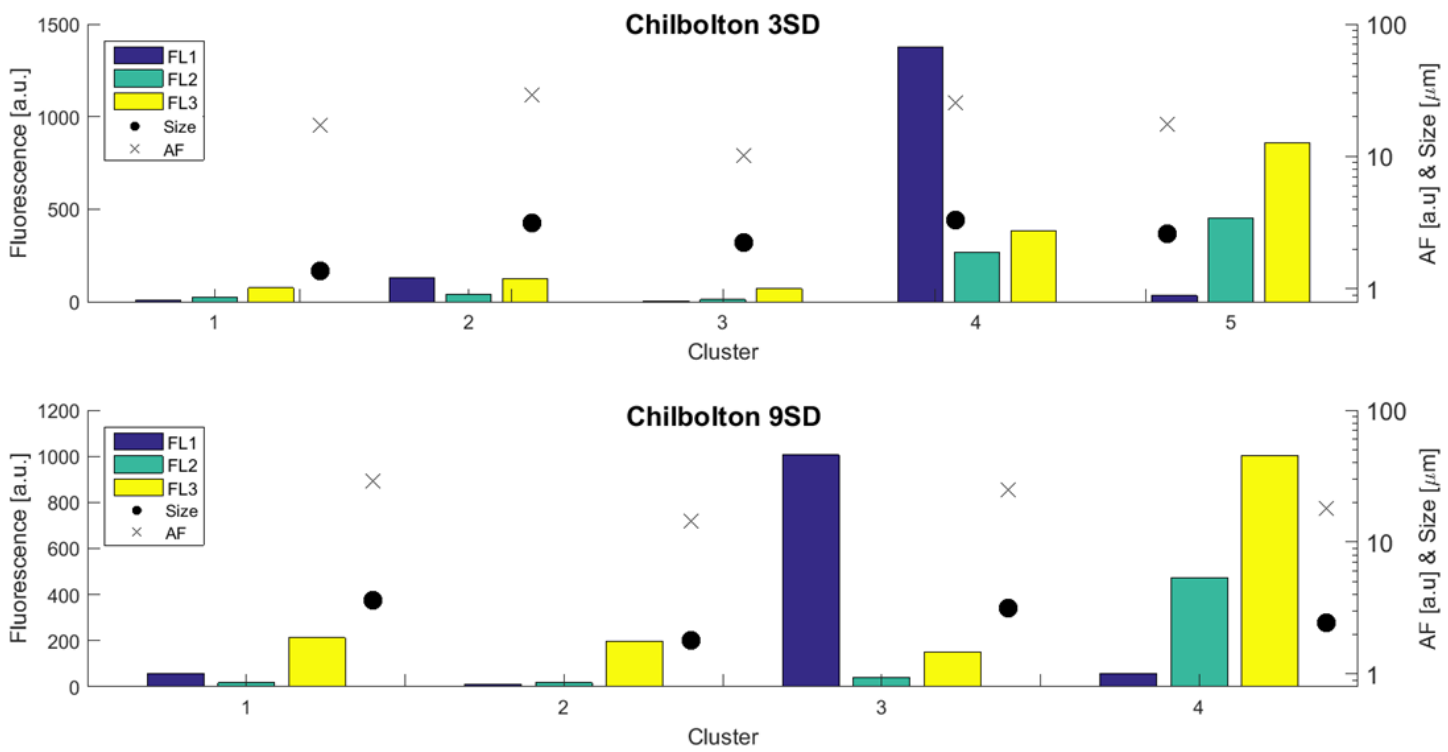

Figure S13: Chilbolton 3SD and 9SD cluster solutions.

\section{FT + 3SD/9SD - Weybourne}
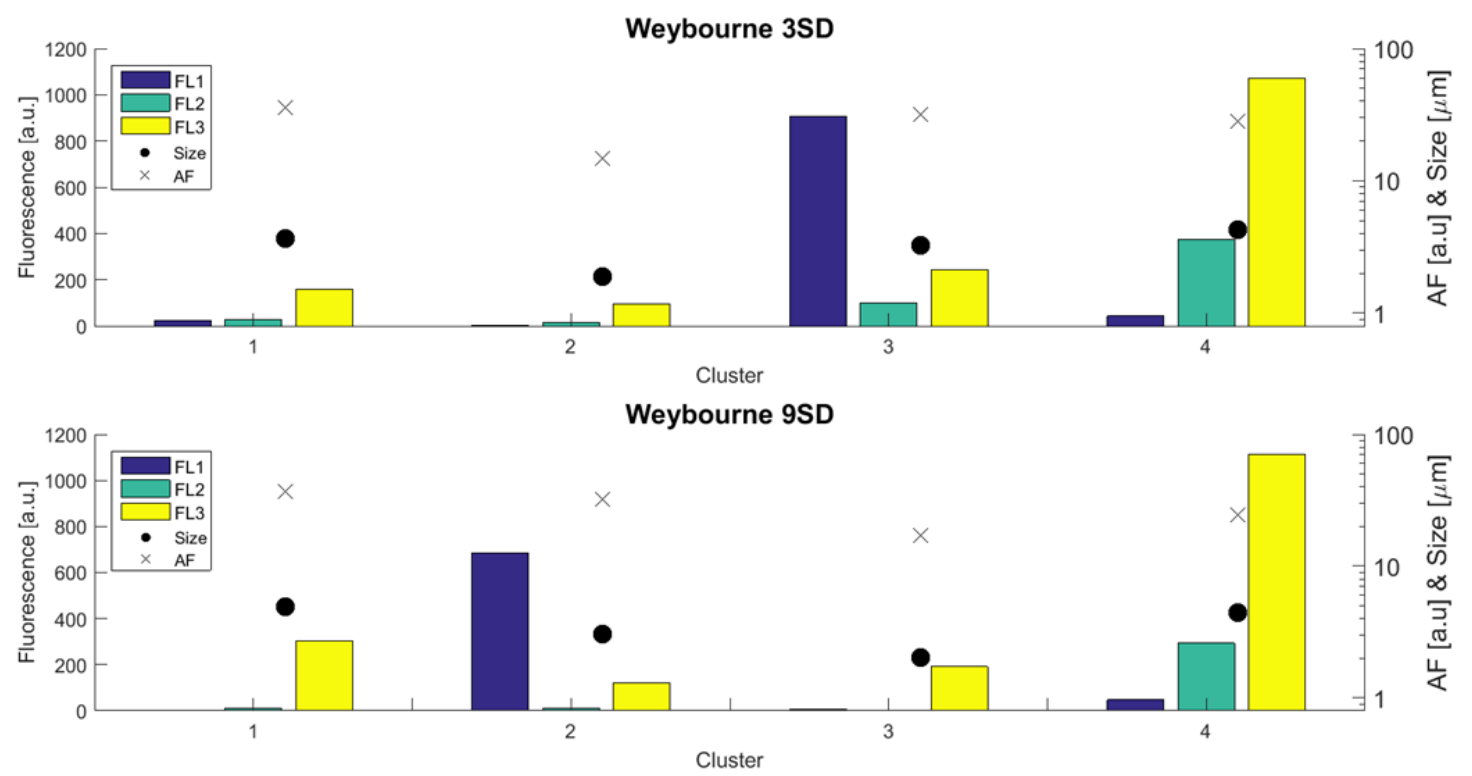

Figure S14: Weybourne 3SD and 9SD cluster solutions. 


\section{FT + 3SD/9SD - Davidstow}
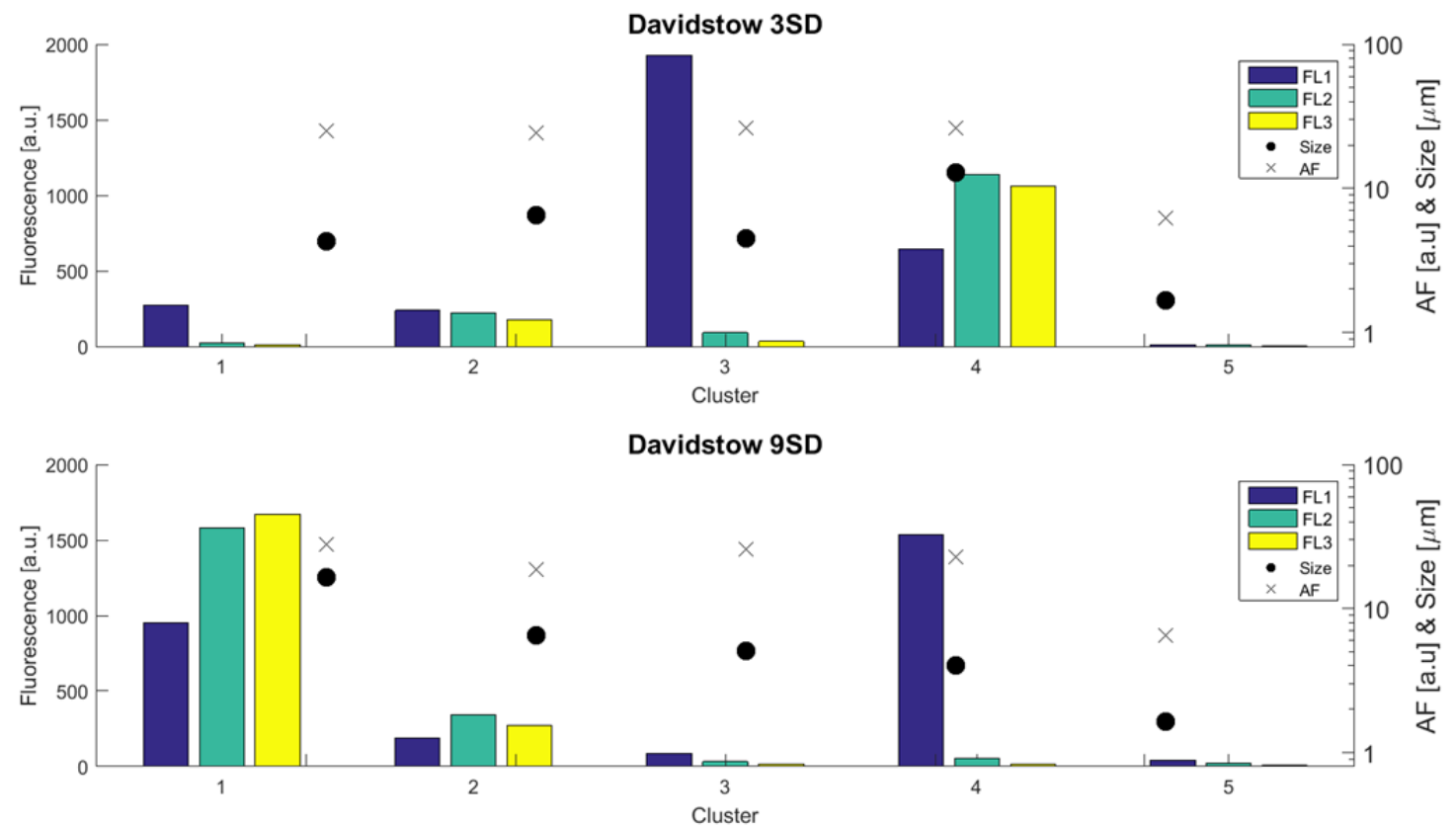

Figure S15: Davidstow 3SD and 9SD cluster solutions.

\section{FT + 3SD/9SD - Capel Dewi}
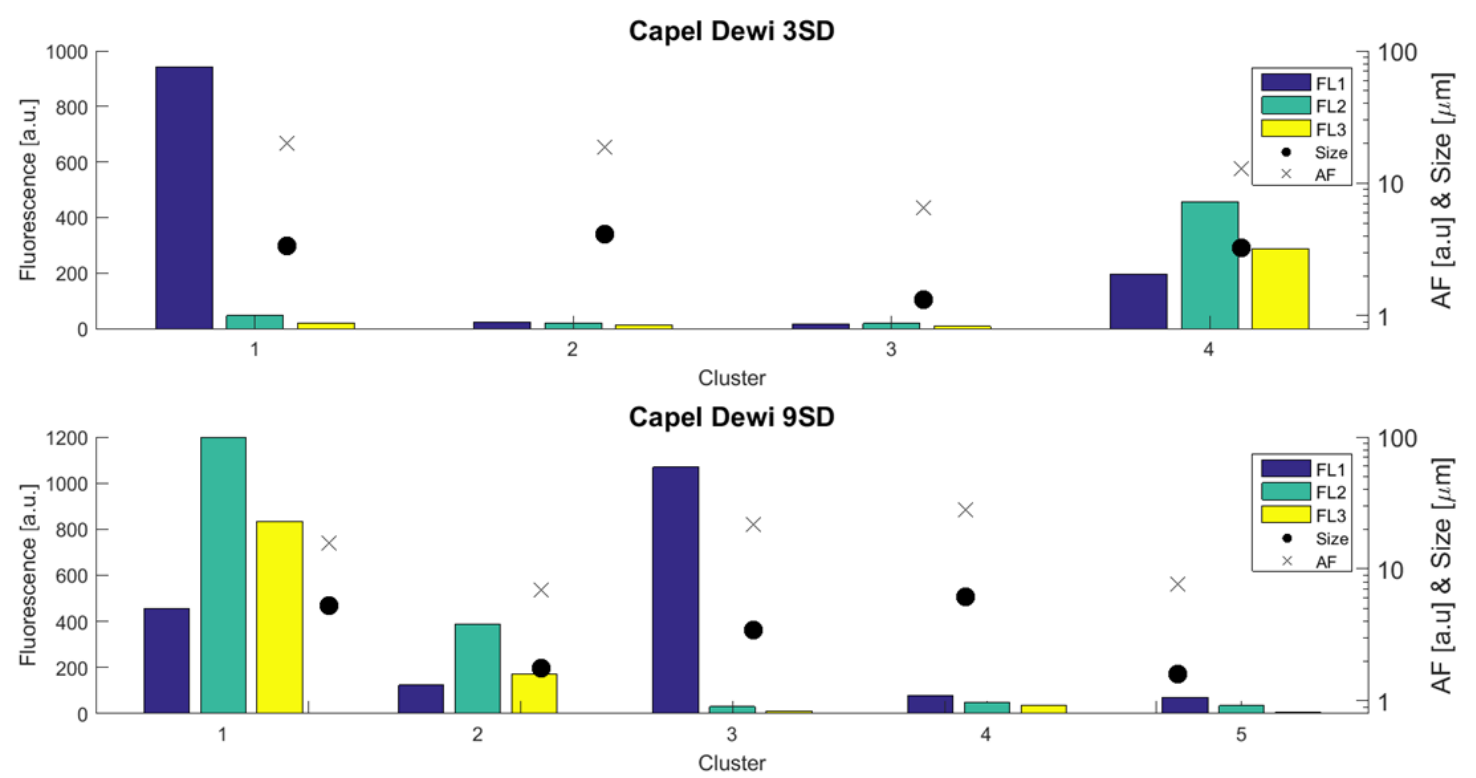

Figure S16: Capel Dewi 3SD and 9SD cluster solutions. 